\title{
Aqueous Sulfur Passivation of N-Type GaSb Substrates Studied by Photoluminescence Spectroscopy
}

\author{
Delia M. Hurtado-Castañeda1, José L. Herrera-Perez², José S. Arias-Cerón ${ }^{3}$, \\ Claudia Reyes-Betanzo1, Patricia Rodriguez-Fragoso3 ${ }^{3}$, Julio G. Mendoza-Alvarez ${ }^{3}$ \\ ${ }^{1}$ Electronics Department, National Institute of Astrophysics, Optics and Electronics, Puebla, México \\ ${ }^{2}$ Instituto Politécnico Nacional-UPIITA, México DF, México \\ ${ }^{3}$ Physics Department, Cinvestav-IPN, México DF, México \\ Email: ${ }^{*}$ jmendoza@fis.cinvestav.mx
}

Received 20 May 2014; revised 23 June 2014; accepted 3 July 2014

Copyright (C) 2014 by authors and Scientific Research Publishing Inc.

This work is licensed under the Creative Commons Attribution International License (CC BY). http://creativecommons.org/licenses/by/4.0/

c) (i) Open Access

\begin{abstract}
In this work the influence of aqueous sulfur passivation on the surface of n-type (100) GaSb single crystals has been studied through low-temperature photoluminescence (PL) characterization. The samples were passivated at different times using aqueous solutions of sodium sulfide. PL spectroscopy was used to determinate the optimum time of sulfur passivation, through the measurement of the PL intensity for the different passivation times. For the samples measured, the PL spectra show the presence of two emission bands, whose intensity and energy position change for the different passivation times of the GaSb samples. According to the PL results, a passivation surface treatment of 6 min shows the highest PL intensity spectrum.
\end{abstract}

Keywords

GaSb, Photoluminescence Spectroscopy, Sulfur Passivation

\section{Introduction}

The development of GaSb-based semiconductor materials has been the subject of a wide research effort because of the great potential they have for the fabrication of optoelectronic devices in the near-infrared portion of the spectrum, such as lasers, photodetectors, solar cells and high-efficiency thermophotovoltaic cells, among others [1].

"Corresponding author.

How to cite this paper: Hurtado-Castañeda, D.M., Herrera-Perez, J.L., Arias-Cerón, J.S., Reyes-Betanzo, C., Rodriguez-Fragoso, P. and Mendoza-Alvarez, J.G. (2014) Aqueous Sulfur Passivation of N-Type GaSb Substrates Studied by Photoluminescence Spectroscopy. Natural Science, 6, 963-967. http://dx.doi.org/10.4236/ns.2014.612088 
Semiconductor compounds based on GaSb are very promising for infrared applications, since when GaSb crystals are used as substrates for devices, it is possible to have the lattice match of III-V ternary and quaternary solid solutions covering the optical range from 0.8 to $4.3 \mu \mathrm{m}$ [1]. Surface preparation of the substrate is a critical issue in the fabrication and optimization of devices. As it is well known, device efficiency strongly depends on the interface quality, such as defect-free abrupt interfaces which are built with planar surfaces free of oxides and defects. Interfaces with a high density of defects degrade very fast and are responsible for leak currents. GaSb is highly reactive at room temperature and easily oxidizes in the presence of atmospheric oxygen producing native oxides such as $\mathrm{Sb}_{2} \mathrm{O}_{3}$ and $\mathrm{Ga}_{2} \mathrm{O}_{3}$. This increases the growth of an elemental antimony monolayer which is responsible for a drastic increase in the surface recombination velocity and the leak current. These could limit the semiconductor device performance [2] [3]. The passivation process should result in a semiconductor surface less chemically active with a reduced density of recombination centers with decreasing activity [4]. Several wet and dry passivation methods have been studied to improve the GaSb surface characteristics [5] [6]. Wet passivation techniques offer the advantages of being a simple and economical method in which we can control the etching speed through the temperature and reactant density. Sulfur wet passivation on the GaSb surface opens new possibilities for the development of optoelectronic devices fabricated using liquid phase epitaxy and molecular beam epitaxy growth methods [4] [7].

In this work, we have studied the passivation process of the GaSb single crystals using a solution of sodium sulfide $\left(\mathrm{Na}_{2} \mathrm{~S}: 9 \mathrm{H}_{2} \mathrm{O}\right)$ using different immersion times. The effect of different treatment times of the GaSb surface on the surface recombination velocity was investigated using low-temperature photoluminescence (PL) spectroscopy. By measuring the PL intensity change as a function of the aqueous treatment times we can optimize the sulfur passivation time.

\section{Experimental Procedure}

Experiments were performed on n-type (100) GaSb single crystals doped with Te at concentrations of around 5 $\times 10^{17} \mathrm{~cm}^{-3}$. GaSb crystals were degreased using boiling acetone and methanol solutions and rinsed in cold methanol. Native oxides and organic residues were eliminated by immersing them in sulfuric acid $\left(\mathrm{H}_{2} \mathrm{SO}_{4}\right)$, hydrofluoric acid (HF) and finally in hydrochloric acid (HCl). After each step, samples were rinsed in methanol instead of the usual deionized water rinsing. This cleaning procedure method was applied to all samples under study. After the initial cleaning process, a series of GaSb crystals were immersed in an aqueous solution of sodium sulfide $\left(\mathrm{Na}_{2} \mathrm{~S}: 9 \mathrm{H}_{2} \mathrm{O}\right)$ with $\mathrm{M}=1.0(\mathrm{pH} 13.9)$ for different times in the range 0 to 15 minutes. This was in order to find out, through the use of PL, the optimal passivation time which minimizes the surface recombination velocity. Low temperature PL measurements for the different samples treated at different passivation times were performed by placing the sample in the cold finger of a He-closed cycle cryostat to record PL spectra at a temperature of $20 \mathrm{~K}$. As the exciting source, we used the $488 \mathrm{~nm}$-line of an $\mathrm{Ar}^{+}$ion laser with a nominal power of $50 \mathrm{~mW}$ chopped at a frequency of $83 \mathrm{~Hz}$. PL signal was focused to the slit entrance of an Acton monochromator and detected with an InSb infrared detector EG \& G Judson cooled at liquid nitrogen temperature. Signal was amplified by a lock-in (SRS-SR850) and finally the PL spectrum was displayed in a PC computer through a LabView software, as shown in Figure 1.

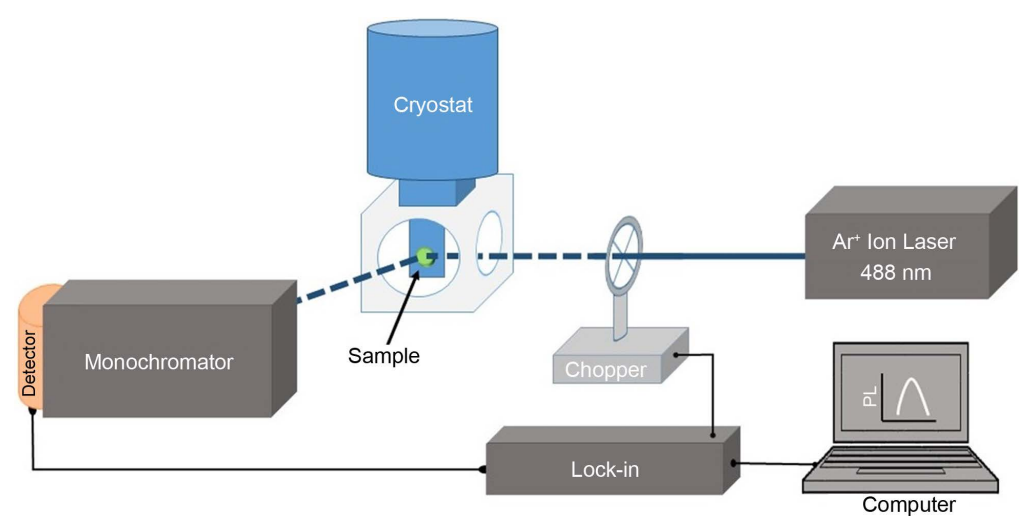

Figure 1. Low temperature photoluminescence setup used to measure the luminescence efficiency of the GaSb samples passivated with different times using sodium sulfide solutions. 


\section{Results and Discussion}

In Figure 2 we show the photoluminescence spectra measured at $20 \mathrm{~K}$ for samples subjected to immersion in the $\mathrm{Na}_{2} \mathrm{~S}$ aqueous solution with a pH of about 13.9 for times of $0,2,4,6,9$ and 15 minutes, respectively. Comparing the PL spectra shown in Figure 2, we can observe that the intensity and the peak position of the bands change for the passivated samples. PL signal intensity is 7 times higher than the PL intensity for the untreated sample, and it has a shift to higher energies of around $15 \mathrm{meV}$. The highest PL intensity occurs for the GaSb sample corresponding to a passivation time of $6 \mathrm{~min}$, and it has a peak centered at $692 \mathrm{meV}$. The passivation process involves two competitive mechanisms: a layer-by-layer etching and the formation of the passivation coating; for short passivation times the native oxides are removed and the surface recombination velocity is reduced. For longer passivation times the etching of the surface create more surface states which are responsible for a decrease in the PL efficiency. The PL spectra show that for a 6-min passivation time we obtain an optimal surface, and that increasing $\mathrm{Na}_{2} \mathrm{~S}$ treatment produces a non-monotonic etching-passivation process, as has been reported before [7].

The PL intensity depends strongly on the non-radiative surface recombination; when the sample is excited by the $\mathrm{Ar}^{+}$ion laser light, there is a production of electron-hole pairs near to the surface. The pairs can be radiatively recombined if we have a passivated surface which has a significant reduction in the trap density, in such a way that there is an increase in the luminescence efficiency. We also observe that the PL emission bands are assymetric, and that they can be de-convoluted into two bands, one with energy peak in the range between 690 and $700 \mathrm{meV}$, and the other one with energy peak between 720 and $740 \mathrm{meV}$.

In Figure 3 we show the variation in the peak energy of the PL spectra obtained by a Gaussian de-convolution of the PL spectra for the different passivation times. The low energy PL band (A) is associated to a deep acceptor levels; whereas the high energy PL band (B) is related to recombination involving ionized residual acceptors levels [8]-[10]. As the passivation time increases, the peak energy of the transition A shows a blue-shift from $688 \mathrm{meV}$ until its stabilization around $694 \mathrm{meV}$. The opposite effect is observed for the PL band B, associated to ionized residual acceptors, which shifts to lower energies when the passivation time increases, changing from around $716 \mathrm{meV}$ until its stabilization around $701 \mathrm{meV}$. After a passivation time of 6 min, we do not observe a significant shift in the peak energy of both emission bands.

In order to compare the relative contribution of the PL signal for each one of the two transitions, the PL spectra were normalized. In Figure 4 we show the evolution in the emission efficiency for transitions A and B as a function of the passivation time. We can observe two behaviors: for the B transition associated to ionized residual acceptors there is a gradual increase in the efficiency and becomes dominant after 6 min, reaching a saturation. An opposite behavior is observed for the those transitions associated to deep acceptors, their efficiency decreases as the passivation time increases, becoming one order of magnitude smaller than transition B.

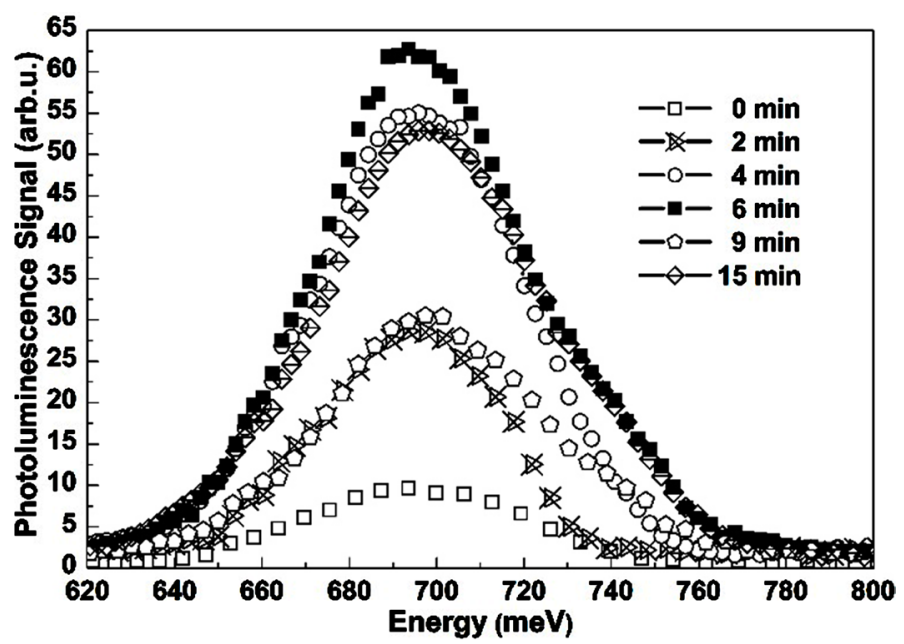

Figure 2. PL spectra for GaSb substrates treated by their immersion in a $\mathrm{Na}_{2} \mathrm{~S}$ solution with a $\mathrm{pH}$ of 13.9 for times of $0,2,4,6,9$ and $15 \mathrm{mi}-$ nutes. 


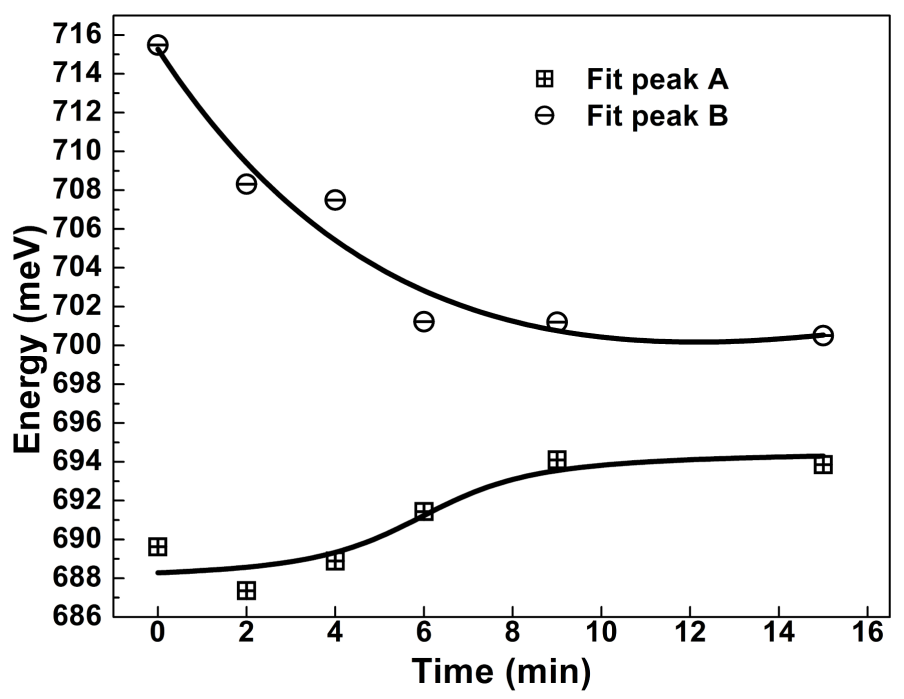

Figure 3. Peak energy variation for A and B transitions as a function of the passivation time. Peak A has a blue-shift from about $688 \mathrm{meV}$ up to $694 \mathrm{meV}$. Peak B shows a red-shift from about $716 \mathrm{meV}$ down to $701 \mathrm{meV}$.

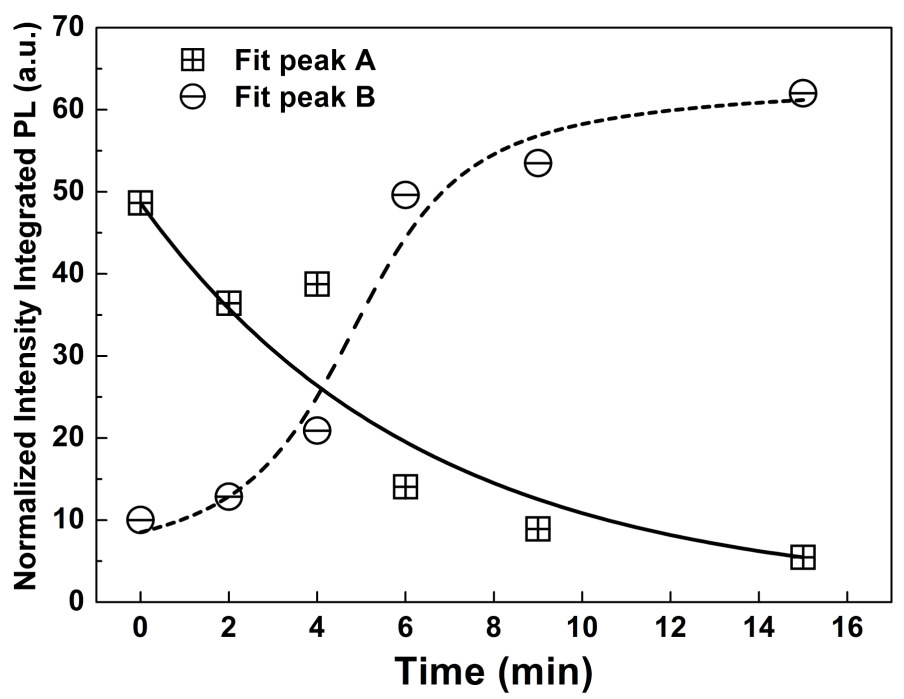

Figure 4. Relative efficiencies for the A and B transitions as a function of the passivation time.

\section{Conclusion}

In summary, we have presented the study of the passivation of GaSb single crystal substrates using an aqueous solution of $\mathrm{Na}_{2} \mathrm{~S}$ as a function of the immersion time. From the study of the variation of the PL intensity we optimized the immersion time of the sample in the solution. The PL intensity for the sample treated for 6 min was 7 times higher than the untreated sample. The PL spectra as a function of the passivation time show two main transitions: one has a blue-shift from about $688 \mathrm{meV}$ up to $694 \mathrm{meV}$, and the other transition shows a red-shift from about $716 \mathrm{meV}$ down to $701 \mathrm{meV}$. Finally we described the variation as a function of the passivation time of the relative contribution to the PL intensity of the different transitions involved in the passivation process.

\section{Acknowledgements}

This research has been partially supported by the ICyTDF and CONACYT, México. This work was conducted a 
Sabbatical year of JLHP at the INAOE.

\section{References}

[1] Dutta, P.S., Bhat, H.L. and Kumar, V. (1997) The Physics and Technology of Gallium Antimonide: An Emerging Optoelectronic Material. Journal of Applied Physics, 81, 5821-5870. http://dx.doi.org/10.1063/1.365356

[2] Pérotin, M., Coudray, P., Gouskov, L., Luquet, H., Llinarès, C., Bonnet, J.J., Soonckindt, L. and Lambert, B. (1994) Passivation of GaSb by Sulfur Treatment. Journal of Electronic Material, 23, 7-12. http://dx.doi.org/10.1007/BF02651260

[3] Liu, Z.Y., Hawkins, B. and Kuech, T.F. (2003) Chemical and Structural Characterization of GaSb(100) Surfaces Treated by HCl-Based Solutions and Annealed in Vacuum. Journal of Vacuum Science \& Technology B, 21, 71-77. http://dx.doi.org/10.1116/1.1532023

[4] Papis-Polakowska, E. (2005/2006) Surface Treatments of GaSb and Related Materials for the Processing of MidInfrared Semiconductor Devices. Electron Technology: Internet Journal, 37/38, 1-34.

[5] Dutta, P.S., Koteswara Rao, K.S.R., Bhat, H.L. and Kumar, V. (1995) Effect of Ruthenium Passivation on the Optical and Electrical Properties of Gallium Antimonide. Journal of Applied Physics, 77, 4825-4827. http://dx.doi.org/10.1063/1.359407

[6] Díaz-Reyes, J., Corona-Organiche, E., Herrera-Pérez, J.L. and Mendoza-Álvarez, J.G. (2001) Passivation of GaSb Single Crystal Surfaces Studied by Photoluminescence. Modern Physics Letters B, 15, 804-808. http://dx.doi.org/10.1142/S0217984901002579

[7] Kunitsyna, E.V., L’vova, T.V., Dunaevskii, M.S., Terent'ev, Ya.V., Semenov, A.N., Solov’ev, V.A., Meltser, B.Ya., Ivanov, S.V. and Yakovlev, Yu.P. (2010) Wet Sulfur Passivation of GaSb(100) Surface for Optoelectronic Applications. Applied Surface Science, 256, 5644-5649. http://dx.doi.org/10.1016/j.apsusc.2010.03.027

[8] Iyer, S., Small, L., Hegde, S.M., Bajaj, K.K. and AbulFadl, A. (1995) Low-Temperature Photoluminescence of Te Doped GaSb Grown by Liquid Phase. Journal of Applied Physics, 77, 5902-5909. http://dx.doi.org/10.1063/1.359170

[9] Iyer, S., Hegde, S., Bajaj, K.K., AbulFadl, A. and Mitchel, W. (1993) Photoluminescence Study of Liquid Phase Electroepitaxially Grown GaInAsSb on (100). Journal of Applied Physics, 73, 3958-3961. http://dx.doi.org/10.1063/1.352859

[10] Nicholas, D.J., Lee, M., Hamilton, B. and Singer, K.E. (1987) Spectroscopic Studies of Shallow Defects in MBE GaSb. Journal of Crystal Growth, 81, 298-303. http://dx.doi.org/10.1016/0022-0248(87)90408-8 
Scientific Research Publishing (SCIRP) is one of the largest Open Access journal publishers. It is currently publishing more than 200 open access, online, peer-reviewed journals covering a wide range of academic disciplines. SCIRP serves the worldwide academic communities and contributes to the progress and application of science with its publication.

Other selected journals from SCIRP are listed as below. Submit your manuscript to us via either submit@scirp.org or Online Submission Portal.
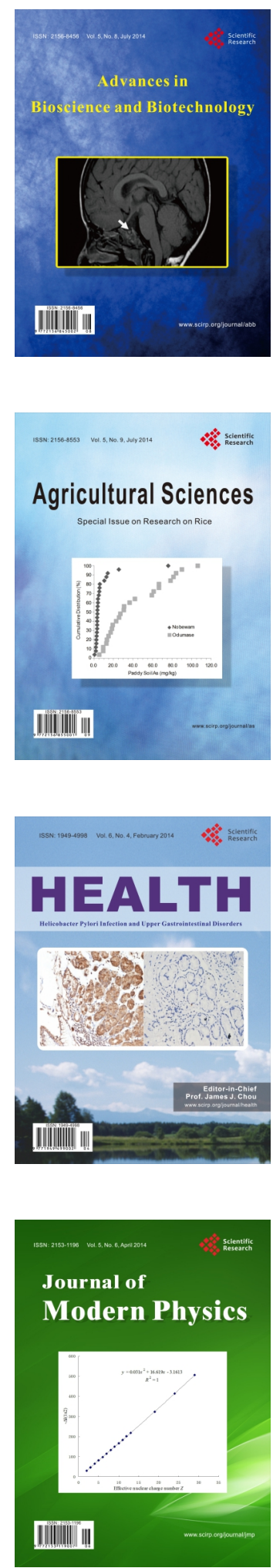
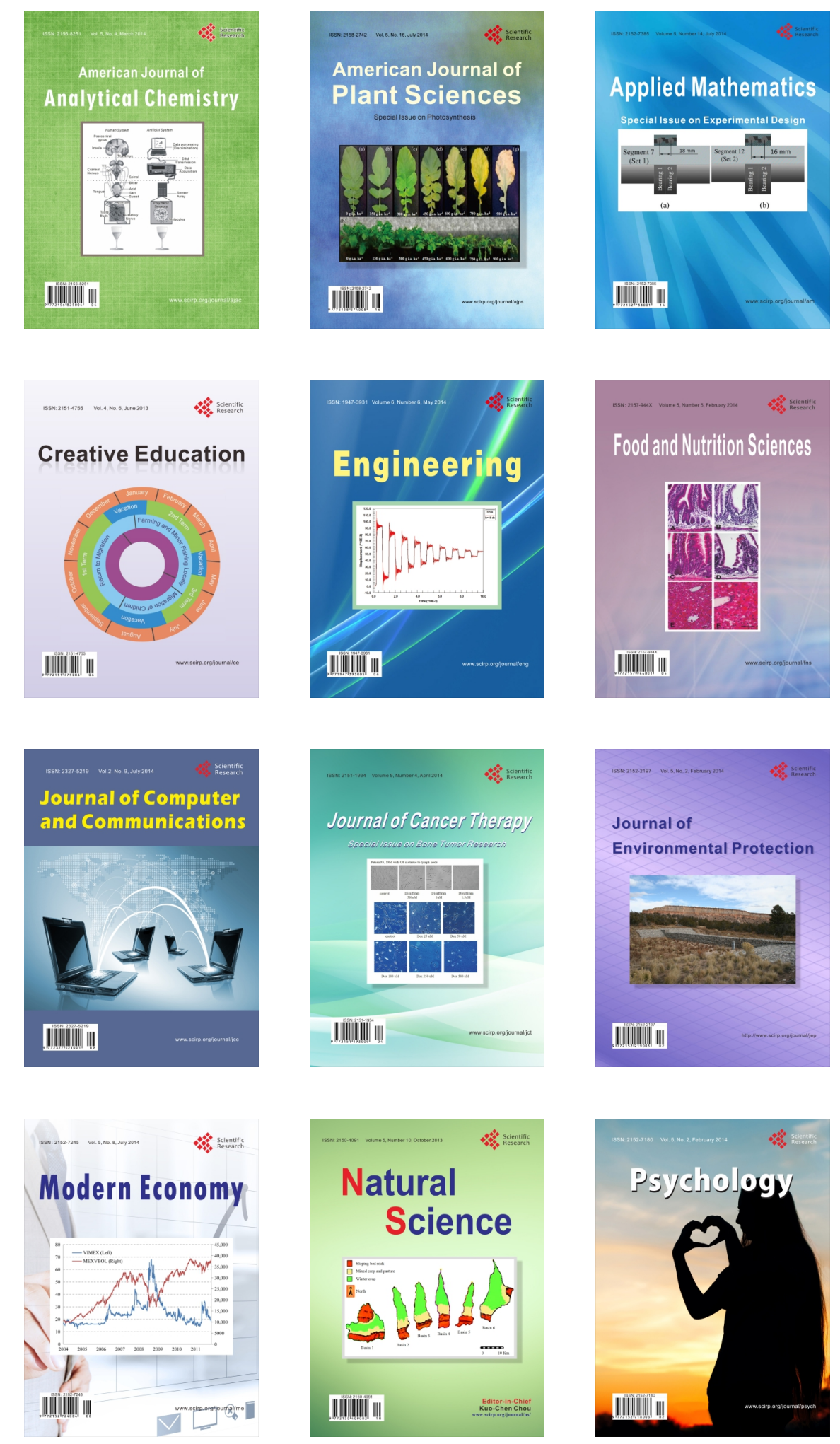